\title{
VIBROSTABILITY IMPROVEMENT USING THE ACTIVE CLAMP IN MACHINING
}

\begin{abstract}
SUMMARY
In this paper the results of simulation of vibration suppression during machining are presented. Two versions of the active clamp system were examined. In the case when the work-piece vibration dominates one direction, the active clamp system with 1 degree of freedom (1-DOF) can be used. Also, a 2-DOF sys-tem is proposed to show the effectiveness of the active clamp system for a complex vibration scenario.
\end{abstract}

Keywords: stability, chatter, active clamp

ZWIĘKSZENIE GRANICY STABILNOŚCI W TRAKCIE SKRAWANIA POPRZEZ ZASTOSOWANIE AKTYWNEGO UCHWYTU OBRÓBKOWEGO

$W$ artykule przedstawiono koncepcje modyfikacji wlaściwości dynamicznych przedmiotu obrabianego poprzez zastosowanie aktywnego uchwytu mocujacego. Zaleta prezentowanego roz-wiazania, w porównaniu do innych metod, jest możliwość pracy z przedmiotami o dużej różnorodności. Ponadto, nie ma potrzeby wprowadzania dodatkowych modyfikacji w obrabianym przed-miocie. W pracy przedstawione zostaty wyniki symulacji numerycznych ukazujace redukcję amplitudy drgań w trakcie obróbki dla dwóch wariantów konstrukcyjnych aktywnego uchwytu.

Slowa kluczowe: stabilność, drgania samowzbudne, aktywny uchwyt

\section{INTRODUCTION}

The high level of vibration during machining has a negative influence on machine tools and the cutting process. Moreover, high vibration may cause tool life shortening, quality of machined surface worsening and productivity decrease. Operational speed and machined surface depends strongly on the dynamic stability of three components of the machine tool-cutting system: the cutting tool, the machine tool structure, and the work-piece clamping system. To assure stable machining, parameters of the cutting process have to be tuned with lower productivity level. For this reason different types of systems are developed for suppressing workpiece vibration. Liu and Rouch (1991) and by Tarng et al. (2000) propose to use an appropriately tuned eliminator which is attached to the work-piece. The methodology of the vibration absorber tuning with the view of eliminating self-excited vibrations was proposed by Sims (2007). On the basis of time domain milling simulations he increased the stability limit by $40-50 \%$. An additional modification of the work-piece is necessary when a vibration absorber is used. The paper describes a modification of the work-piece dynamic properties using an active clamp system. A great advantage of the proposed system is its capability of clamping various work-pieces. Moreover, the active clamp system does not require a modification of the workpiece.

In this paper the results of a simulation of vibration suppression during machining are presented. Two versions of the active clamp system are examined. In the case when the work-piece vibration dominates one direction the active clamp system with 1 degree of freedom (1-DOF) can be used. Also, 2-DOF system is proposed to show the effectiveness of the active clamp system for a complex vibration scenario.

\section{ONE DEGREE}

\section{OF FREEDOM ACTIVE CLAMP SYSTEM}

The idea of the 1-DOF clamp system is presented in Figure 1. The work-piece is attached to the moving plate. This type of work-piece exhibits high vibration amplitude during machining only in a direction parallel to the feed $x_{2 y}$, therefore the 1-DOF clamp system is sufficient to suppress vibration.

In order to reduce vibration the piezoactuators are used as active elements. The operating point of the piezoactuators is chosen in half of max stroke to enable movement in both directions. The regenerative effect is responsible for the occurrence of the self-excited vibrations and leading to its instability. The frequency of self-excited vibration is strongly connected to the natural frequencies of the workpiece. Therefore, the piezoactuators are used to increase damping, especially in the natural frequency range. To achieve this goal the state space model of the work-piece mounted in the active clamp system is determined (1), and on this basis the LQG controller was designed.

$$
\begin{aligned}
& \dot{\mathbf{x}}=\mathbf{A x}+\mathbf{B u} \\
& \mathbf{y}=\mathbf{C x}+\mathbf{D u}
\end{aligned}
$$

\footnotetext{
* Institute of Manufacturing Engineering,West Pomeranian University of Technology Szczecin; arkadiusz.parus@zut.edu.pl; bartosz.powalka@zut.edu.pl
} 


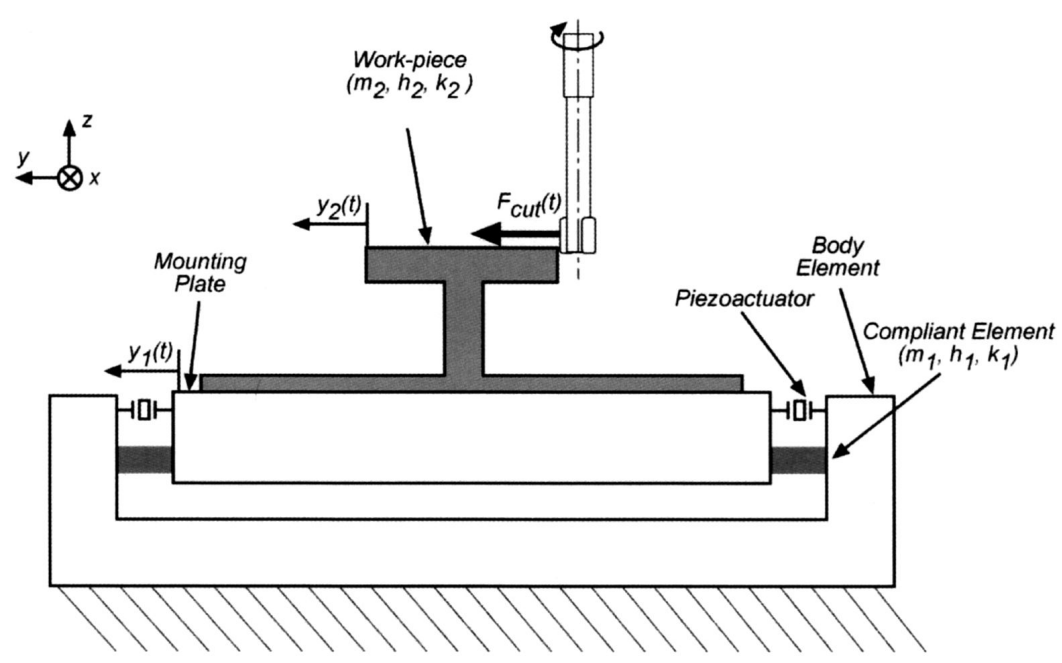

Fig. 1. Workpiece mounted on a 1-DOF active clamp system

where:

$\mathbf{A}=\left[\begin{array}{cccc}0 & 1 & 0 & 0 \\ -\frac{k_{1}+k_{p}+k_{2}}{m_{1}} & -\frac{h_{1}+h_{2}}{m_{1}} & \frac{k_{2}}{m_{1}} & \frac{h_{2}}{m_{1}} \\ 0 & 0 & 0 & 1 \\ \frac{k_{2}}{m_{2}} & \frac{h_{2}}{m_{2}} & -\frac{k_{2}}{m_{2}} & -\frac{h_{2}}{m_{2}}\end{array}\right]$,

$\mathbf{B}=\left[\begin{array}{cc}0 & 0 \\ \frac{k_{p} n d_{33}}{m_{1}} & 0 \\ 0 & 0 \\ 0 & \frac{1}{m_{2}}\end{array}\right], \quad \mathbf{x}=\left[\begin{array}{llll}y_{1} & \dot{y}_{1} & y_{2} & \dot{y}_{2}\end{array}\right]^{T}$,

$\mathbf{C}=\left[\begin{array}{llll}1 & 0 & 0 & 0 \\ 0 & 0 & 1 & 0\end{array}\right]$,

$\mathbf{D}=\mathbf{0}, \quad \mathbf{u}=\left[\begin{array}{c}\mathrm{U}_{\mathrm{p}} \\ \mathrm{F}_{\text {cut }}\end{array}\right]$

$k_{p}-$ piezostack stiffness coefficient,

$d_{33}$ - piezoelectric constant,

$n$ - number of piezostack layers,

$k_{1}, h_{1}, m_{1}-$ stiffness, damping and mass of the clamp system,

$k_{2}, h_{2}, m_{2}-$ stiffness, damping and mass of the work-piece,

$U_{p}-$ control voltage of the piezoactuator

$F_{c u t}$ - cuting force from the mechanistic model (Jayaram et al. 2001).

The inputs of the object are: piezo voltage $U_{p}$ and cutting force $F_{c u t}$ which is treated as a disturbance. The weight matrix in the cost function are chosen to assure that the amplitude of the work-piece vibration is low and the control signal is within acceptable range. In Figure 2, the frequency response function for machining with and without an active clamp system are compared. Significant increasing of the damping in the vicinity of natural frequency can be observed with the LQG controller.

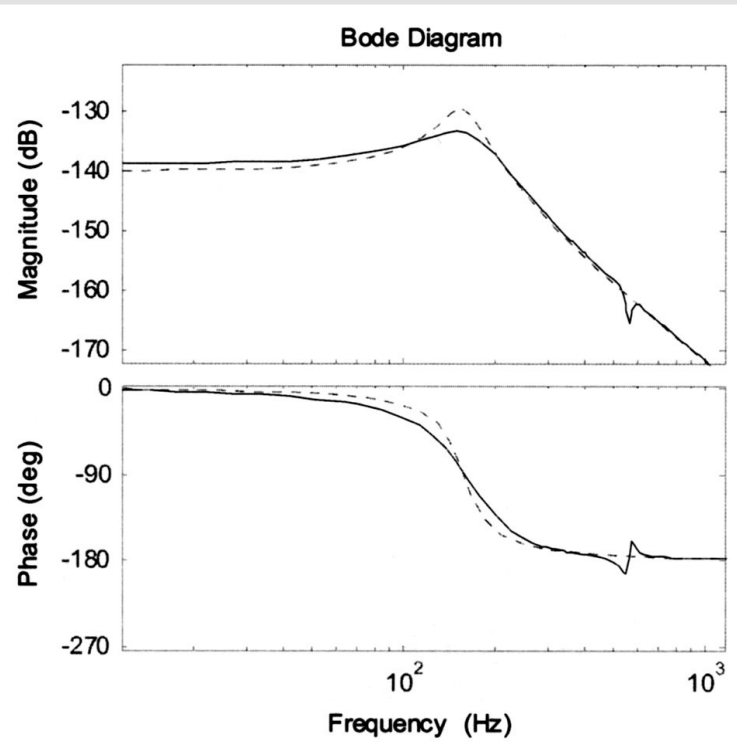

Fig. 2. FRF for work-piece mounted in a 1-DOF active clamp with (a solid line) and without (a dash line) LQG control for Y direction

The set of simulations was executed in Matlab/Simulink to check the properties of the clamp system. The simulations were performed in a wide range of parameters to verify the effectiveness of the proposed concept. In all of the results the piezo voltage control signal is within permissible range $\pm 500 \mathrm{~V}$. In Figure 3, the time plots of the simulation results for machining with the work-piece mounted with and without the active clamp system are presented. The simulation was performed with milling parameters: depth of cut $1.8 \mathrm{~mm}$, spindle speed $300 \mathrm{rpm}$ with 8 cutting blades mill. 

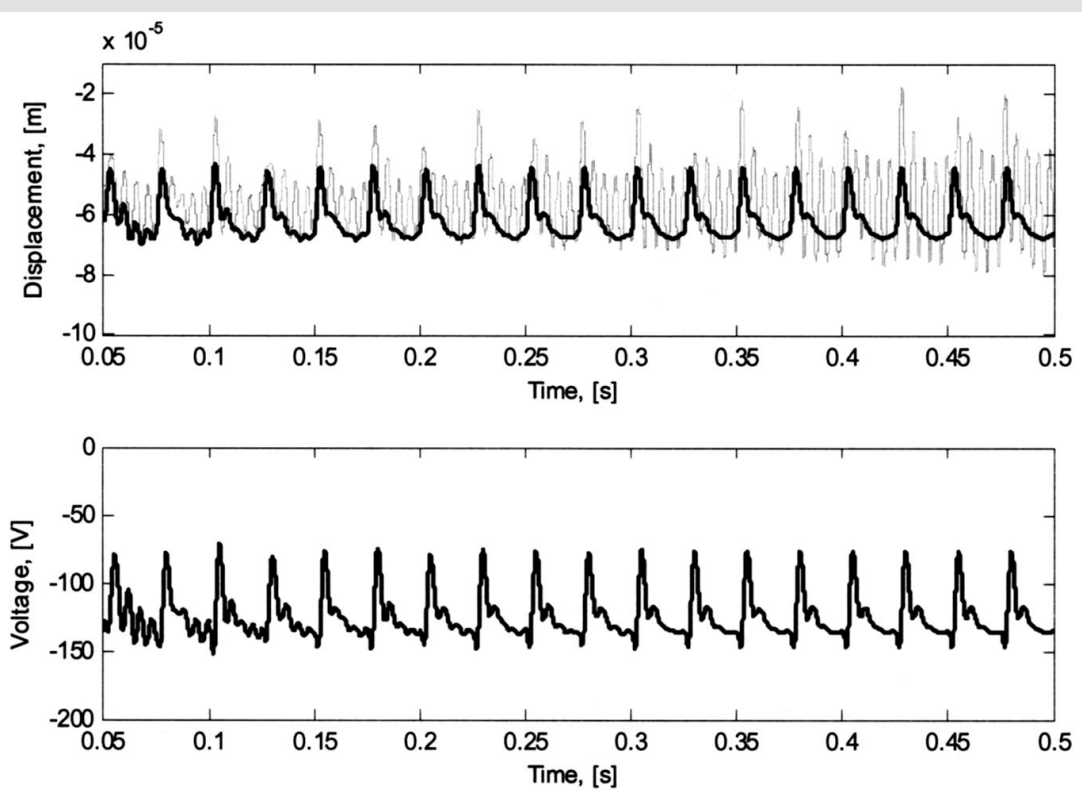

Fig. 3. Work-piece displacement in the $\mathrm{Y}$ direction in the milling process with (black) and without (gray) active clamp system and piezo control voltage

This solution can be useful in the case where the direction of the work-piece vibration can be easily determined. In such cases different types of eliminators can be used as well. The proposed solution has great advantageous in comparison to the eliminator. The operator does not have to perform any additional actions for example, mounting the eliminator to the work-piece etc.

\section{ONE DEGREE \\ OF FREEDOM ACTIVE CLAMP SYSTEM}

The active clamp presented in the last chapter works very effectively with one directional vibration. In some types of work-pieces the direction of the dominant vibration is not obvious, and it can vary during the machining. It causes serious problems with using the 1-DOF systems or eliminators. At the moment that self-excited vibration occur, machining should be stopped, and the work-piece has to be aligned with the eliminator or the 1-DOF active clamp system. In Figure 4, work-piece displacement in the $\mathrm{X}$ and $\mathrm{Y}$ direction are presented when machining is performed on the 1-DOF active clamp system with machining parameters as in Figure 3.
The plot of displacement along the $\mathrm{Y}$ axis is smooth, while in along the $\mathrm{X}$ axis trace regeneration phenomenon can be observed. In this case machine stability can be lost due to vibration in the $\mathrm{X}$ direction. The effectiveness of vibration suppression in complex work-pieces can be improved by using active clamp systems which can act along the XY plane (2-DOF). The proposed idea is presented in Figure 5.

To control piezoactuators in both axis LQG controllers are used. Each controller is designed separately because of the orthogonal properties of the clamp system. FRF magnitudes for both axis with and without LQG controllers are presented in Figure 6. In Figure 7 vibration with control signal along the $\mathrm{X}$ and $\mathrm{Y}$ axis are presented with the same machining parameters. The time scale is changed to allow us to accurately observe the plots. Along both axis the machining process is without significant contribution of trace regeneration. The machining condition is significantly improved and allows us to operate with higher machining parameters. Finally, the stability lobs will be determined to confirm the effectiveness of the proposed 2-DOF active clamp system.

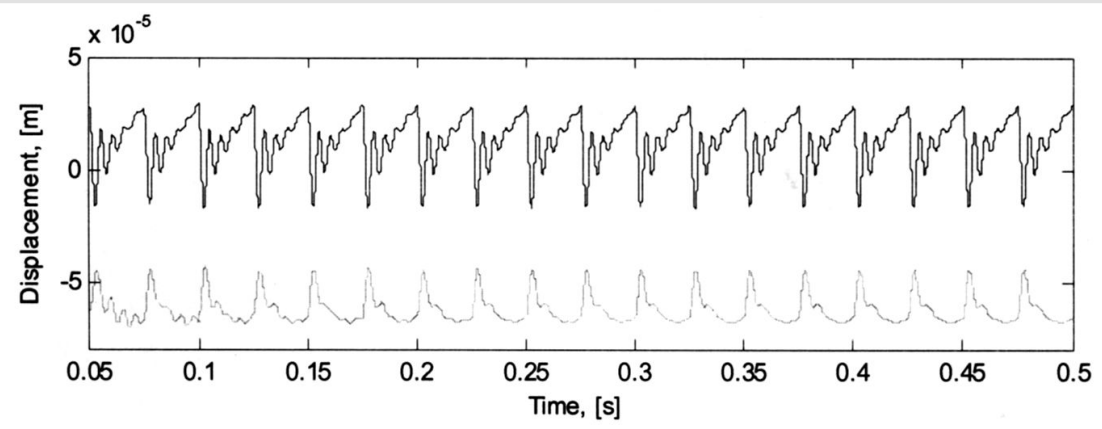

Fig. 4. Work-piece displacement in $\mathrm{X}$ (black) and $\mathrm{Y}$ (gray) direction in the milling process with a 1-DOF active clamp system 


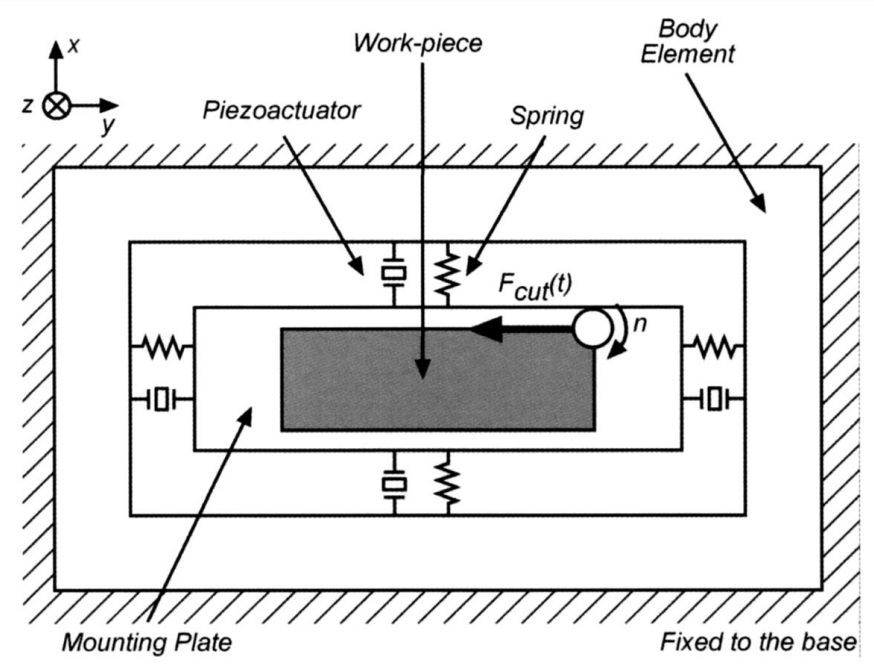

Fig. 5. Work-piece mounted on the 2-DOF active clamp system

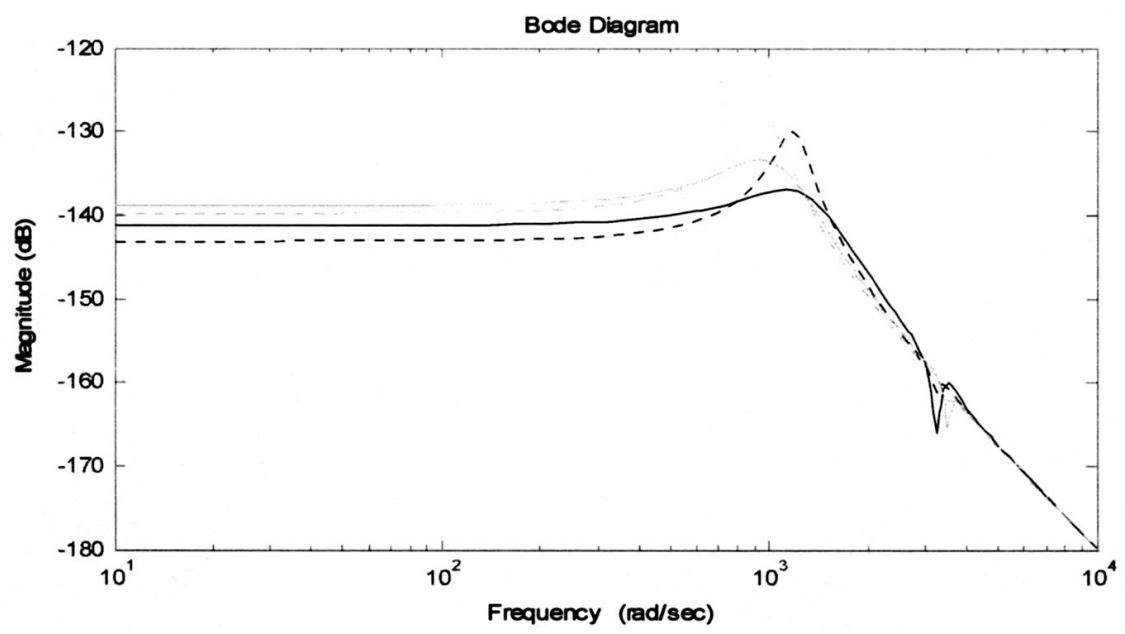

Fig. 6. FRF for work-piece mounted in the active clamp with (solid line) and without (dashed line) LQG control for X (black) and Y (gray) axis
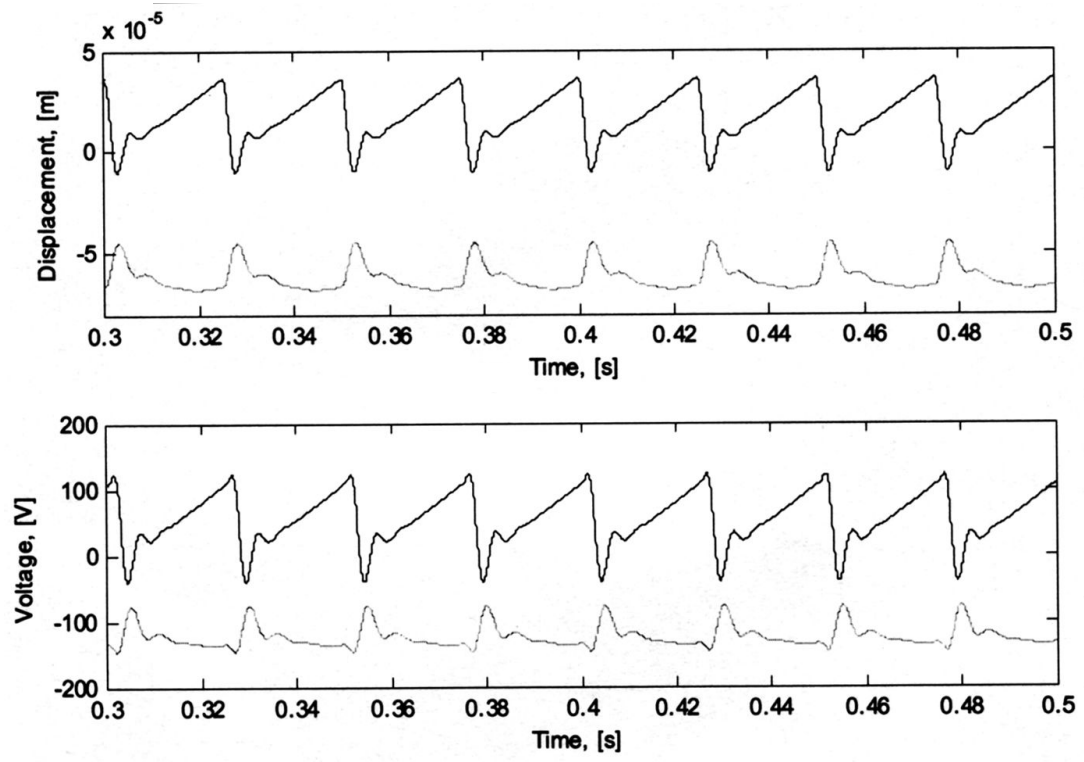

Fig. 7. Work-piece displacement in X (black) and Y (gray) direction in milling process with 2-DOF active clamp system and piezo control voltage 


\section{STABILITY LOBS}

Regenerative chatter vibration is the most common cause of losing stability during machining (Tlusty and Polacek 1963, Tobias and Fishwick 1958). Predicting stability includes determining the so-called stability lobe diagrams. Information about the machine tool's dynamics at the point of contact between the cutting tool and the workpiece with the cutting process model are required in order to determine stability lobes. A model of machine tool dynamics can be represented by matrices of frequency response functions (FRFs) whereas the cutting process model is often presented by means of a mechanistic model in which cutting forces are proportional to the cross-section of the chip. The boundary values of depth of cut and their respective spindle speeds and frequencies of self-excited vibrations can be determined by solving the following equation (Altintas and Budak 1995):

$$
\operatorname{det}\left(\mathbf{I}-a_{p}\left(1-e^{-j \omega_{c} \tau}\right) \mathbf{K}_{C P} \mathbf{G}\left(j \omega_{c}\right)\right)=0
$$

where:

$$
\begin{gathered}
a_{p}-\text { depth of cut, } \\
\omega_{c}=2 \pi f_{c}-\text { chatter frequency, }
\end{gathered}
$$

$$
\begin{aligned}
\tau=60 /(N z)- & \text { tooth pass period }(N- \\
& \text { spindle speed, } z-\text { num- } \\
& \text { ber of cutter teeth), } \\
\mathbf{K}_{C P}- & \text { matrix of averaged cut- } \\
& \text { ting process (Altintas } \\
& \text { and Budak 1995), }
\end{aligned}
$$

$\mathbf{G}(j \omega)=\left[\begin{array}{ll}G_{x x}(j \omega) & G_{x y}(j \omega) \\ G_{y x}(j \omega) & G_{y y}(j \omega)\end{array}\right]-\begin{aligned} & \text { FRF matrix at chatter } \\ & \text { frequency }\end{aligned}$

The stability lobes diagram of the controlled system was first predicted using equation (2), the cutting process model (Jayaram et al. 2001). The transfer matrix function of the controlled system is determined from equation (1) between cutting force and displacement. Subscripts denote the direction of the acting force and response. In Figure 8, the stability lobs diagram for the work-piece mounted without the active clamp system are presented.

Absolute maximal depth of cut with stable machining is in whole spindle speed range is $\mathrm{a}_{\mathrm{lim}}=0.96[\mathrm{~mm}]$. In Figures 9 and 10, the stability lobs are presented for work-piece mounted with $1-\mathrm{DOF}$ and 2-DOF active clamp, respectively.

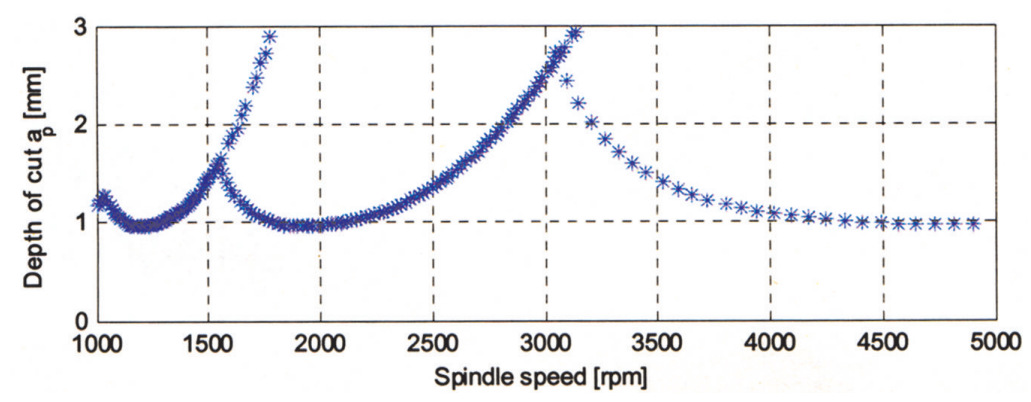

Fig. 8. Stability lobs diagram for the work-piece without the active clam system $\mathrm{a}_{\lim }=0.96[\mathrm{~mm}]$

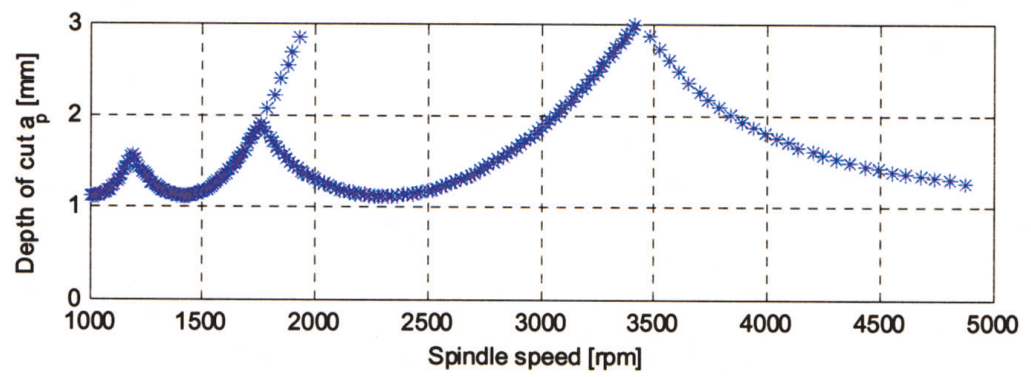

Fig. 9. Stability lobs diagram for the work-piece with the 1-DOF active clamp system $\mathrm{a}_{\lim }=1.26$ [mm]

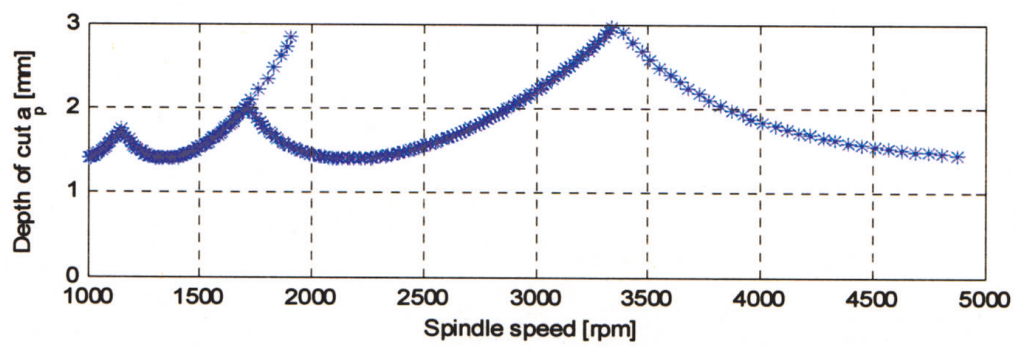

Fig. 10. Stability lobs diagram for the work-piece with the 2-DOF active clamp system $\mathrm{a}_{\lim }=1.40$ [mm] 
In Figure 3, a significant reduction of work-piece vibration can be clearly observed. Moreover, the ultimate stability limit increases to1.26 mm (Fig. 9) and $1.40 \mathrm{~mm}$ (Fig. 10) for the 1-DOF and 2-DOF systems. This enables operating with higher machining parameters. Low level of vibration leads to improved surface quality and longer tool life.

\section{CONCLUSION}

This paper presents a method to reduction of vibration level during machining. To achieve this aim using of active clamp system is proposed. The effectiveness of this concept is verified in numerical simulation. Owing to the piezoactuator it is possible to effectively influence the behavior of the workpiece. Piezo elements ensure high effectiveness of working operation at high frequencies and a given small size. The drawbacks include the substantial cost of an actuator and high voltage power amplifier, but it is realistic to expect that in the foreseeable future the costs of piezo technology can go dramatically down. Active vibration control systems are usually dedicated to a concrete application, and no significant modifications are possible. The presented classic procedures of object identification and regulator synthesis can to a large extend be automated, which leaves a large area of possibility for creating a system with some degree of versatility. Significant chatter reduction was obtained, which can be observed in the time plots. The vibration control system operated effectively at various values of rotational speed, feed rate, and depth of cut. The usefulness of the proposed methods must be confirmed in experimental way.

\section{References}

Altintas Y., Budak E. 1995, Analytical Prediction of Stability Lobes in Milling, Annals of CIRP, 44(1), pp. 357-362.

Jayaram S., Kapoor S.G., Devor R.E. 2001, Estimation of the specific cutting pressures for mechanistic cutting force models, International Journal of Machine Tool and Manufacture, 41, pp. 265-281.

Liu K.J., Rouch K.E. 1991, Optimal passive vibration control of cutting process stability in milling, Journal of Materials Processing Technology, 28, pp. 285-294.

Tlusty J., Polacek M. 1963, The stability of machine tools against self excited vibrations in machining, Proceedings of the ASME Production Engineering Research Conference, pp. 465-474.

Tobias S.A., Fishwick W., Theory of regenerative machine tool chatter, Engineering 1958, 258.

Sims N.D. 2007, Vibration absorbers for chatter suppression: a new analytical tuning methodology, Journal of Sound and Vibration, 301, pp. 592-607.

Tarng Y.S., Kao, J.Y., Lee, E.C. 2000, Chatter suppression in turning operations with a tuned vibration absorber, Journal of Materials Processing Technology, 105(1-2), pp. 55-60. 